\title{
Antegrade Versus Retrograde Cerebral Perfusion for Ascending Aorta and Aortic Arch Replacement: Literature Review
}

\author{
Ahmed Alnajar ${ }^{1}$, Elizabeth Aleong ${ }^{2}$, Muhammad Azhar ${ }^{3}$, Ryan Azarrafiy ${ }^{1}$, and Joseph \\ Lamelas $^{1}$ \\ ${ }^{1}$ University of Miami Miller School of Medicine \\ ${ }^{2}$ University of Florida \\ ${ }^{3}$ Florida International University
}

July 7, 2020

\begin{abstract}
Aortic arch and hemiarch surgery necessitate the temporary interruption of blood perfusion to the brain. Despite its complexity, hemiarch and ascending aortic surgery can be performed via a minimally invasive approach. Due to the higher risk of neurological injury during circulatory arrest, several techniques were developed to further protect the brain during this surgery. We searched the Embase, Medline, and Cochrane databases and identified articles reporting outcomes of antegrade and retrograde cerebral perfusion strategies. Herein, we outline surgical approaches, intra-operative technical considerations, and clinical outcomes of hemiarch and ascending aortic surgery.
\end{abstract}

\section{Introduction}

Neurologic injury has been a major concern in cardiac surgery due to the atherosclerotic burden in the vasculature, cross clamping, and the use of extracorporeal circulation, leading to a significant increase in morbidity, mortality, and cost. ${ }^{1-3}$ Furthermore, disrupting blood flow to the brain will compound on the potential for neurologic complications. The first documented aortic replacement dates back to the 1950s with Denton A. Cooley, Michael DeBakey, and E. Stanley Crawford. ${ }^{4}$ In both 1951 and 1955, aortic arch replacements with the use of bypass shunts and moderate hypothermia were fraught with failure. Only after DeBakey's concept of an early form of antegrade cerebral perfusion in 1957, did surgeons successfully enter a new era of aortic surgery. This was followed by Griepp's introduction of total circulatory arrest under deep hypothermia (up to $14{ }^{\circ} \mathrm{C}$ ) in $1975 .{ }^{5-7}$ With these advances, the risk of stroke and mortality with aortic surgery has greatly improved over the past 70 years. The main strategies that exist today to mitigate the risk of brain injury include deep hypothermic circulatory arrest (DHCA), antegrade cerebral perfusion $(\mathrm{ACP})$, retrograde cerebral perfusion $(\mathrm{RCP})$, as well as a hybrid approach. ${ }^{8}$ The choice in cerebral protection is dependent upon the surgeon's preference and experience with a specific technique, so it is important to recognize the potential advantages or disadvantages of each strategy.

Brain protection strategies

Dating back to the 1970s, the DHCA strategy works by reducing injury-inducing pathways by lowering the cerebral metabolism. ${ }^{9}$ The body is usually cooled to temperatures of $20^{\circ} \mathrm{C}$ or greater. Longer times of DHCA have been correlated to an increased rate of neurological dysfunction, as described by Yan and colleagues (Fig. 1), ${ }^{10}$ so there is usually a need for the use of additional cerebral protection strategies (ACP and RCP). RCP requires connecting the arterial tubing to a cannula placed in the superior vena cava (SVC) and then reversing blood flow to the brain in a retrograde fashion. This approach has been successful in reducing both mortality and morbidity. ${ }^{11}$ An advantage of this strategy is that it provides cold retrograde blood flow to 
the brain during DHCA and therefore allowing for a decreased risk of embolization. ${ }^{12}$ Moderate hypothermic circulatory arrest (MHCA) with temperatures ranging from $24^{\circ} \mathrm{C}$ to $28^{\circ} \mathrm{C}$ can be combined with selective ACP. ${ }^{13}$ Once circulatory arrest is established, one or multiple arch vessels are cannulated and perfused with cold blood in an antegrade fashion. Some studies have suggested that ACP leads to better neurological outcomes when compared with RCP. ${ }^{14}$ The debate between RCP and ACP has been ongoing since the 1990s. Despite the fact that RCP has proven to be effective, many surgeons still prefer using ACP. ${ }^{15} \mathrm{RCP}$ neuroprotective effects are explained by its continuous cerebral cooling, and not from antegrade nutritive blood flow. ${ }^{16}$ RCP's efficacy may also be reduced by the presence of venous valves that require an elevated perfusion pressure, which could cause increase intracranial pressure and subsequently worsen neurological outcomes. ${ }^{17}$ However, RCP does not require exposure or manipulation of the aortic arch vessels, whereas ACP requires insertion of a catheter into the arch vessels, vessel clamping or snaring; which can increase the potential of vessel injury or embolization. Nonetheless, there has not been a clinical study demonstrating that one approach is superior to the other. ${ }^{18} \mathrm{RCP}$ provides improved exposure of the arch vessels, although there is a constant flooding of venous blood return into the operative field, whereas ACP yields a dryer field with catheters potentially obscuring visibility.

1. Surgical techniques

2. Antegrade cerebral perfusion

Antegrade cerebral perfusion can be safely achieved unilaterally through the innominate or right common carotid artery, as well as combined with the left common carotid artery to achieve bilateral ACP. When comparing unilateral and bilateral ACP, most published series quote use of unilateral ACP only if adequate collateralization is demonstrated through backflow from the contralateral carotid artery or if contralateral perfusion is evident by near-infrared spectroscopy (NIRS). ${ }^{4}$ Bilateral ACP may be more advantageous when considering existing conditions such as arterial stenosis, stroke, and other vascular anomalies. Many surgeons prefer bilateral ACP to ensure bihemispherical perfusion due to its documented efficacy and safety beyond 40-50 mins of circulatory arrest. ${ }^{19}$ Alternative cannulation strategies can be utilized to establish antegrade cerebral perfusion. A prosthetic graft can be anastomosed to the right subclavian, innominate, or right common carotid artery. Additionally, balloon occlusion perfusion catheters can be utilized to provide antegrade cerebral perfusion without vessel clamping or snarring. Peripheral cannulation of the axillary artery can be performed to establish cardiopulmonary bypass and subsequent ACP with concomitant insertion of a balloon occlusion perfusion catheter into the carotid artery without directly cannulating supra-aortic vessels. ${ }^{4}$

Retrograde cerebral perfusion

Retrograde cerebral perfusion takes a different approach as cold oxygenated blood is delivered retrograde through a cannula placed in the superior vena cava. ${ }^{19}$ After the patient is cooled to achieve deep hypothermia and circulatory arrest established, RCP can be employed. If a bicaval venous cannulation technique is employed for cardiopulmonary bypass, Y-connectors with limbs are utilized to connect the arterial to the venous lines. These limbs are clamped during the conduct of cardiopulmonary bypass. When beginning to initiate retrograde cerebral perfusion, the SVC cannula is snared and the limb connecting the arterial cannula to the SVC cannula is unclamped. ${ }^{20}$ This enables cold blood to run retrograde into the SVC to perfuse the brain (Fig. 2). A cardiotomy suction is placed in the open thoracic aorta to suction the blood return from the arch vessels. ${ }^{21}$ Ice packs are also placed on the scalp of the patient for additional topical brain cooling. $\mathrm{RCP}$, as well as ACP, has been historically performed via a median sternotomy, upper hemisternotomy, or other partial sternal splitting variations. However, currently, RCP is the only cerebral protection strategy that can be employed through a right mini-thoracotomy minimally invasive ascending aorta and hemiarch surgery. ${ }^{22} \mathrm{~A}$ hybrid approach to these techniques include utilizing 2 separate heater coolers, one for the systemic circulation and one for the cerebral circulation. With this approach, the right carotid artery is exposed in the neck or the innominate artery is exposed from within the chest. Each vessel is directly cannulated and clamped with perfusion coming from a separate tubing connected to the heart lung machine with its own respective heater cooler. Since there are 2 heater coolers, perfusion to the brain can be maintained at 10 degrees $\mathrm{C}$, while perfusion of the body can remain a mild to moderate hypothermia ( 28 degrees $\mathrm{C}$ ). This 
not only allows continuous brain perfusion, but avoids the potential coagulopathy associated with systemic hypothermia.

\section{Discussion}

Improvements to cerebral protection strategies have enabled longer circulatory arrest times when compared to DHCA alone, which limits the safe circulatory arrest time to only 30 minutes. ${ }^{18}$ By incorporating ACP and RCP into the cerebral protection strategy, stroke and mortality rates have been reduced. Although using MHCA with ACP has been the primary neuroprotective strategy in many high-volume aortic centers worldwide, the question of which strategy provides better outcomes in ascending aorta, hemiarch or arch replacement remains an area of significant controversy and debate. Thus, several studies have attempted to answer which cerebral protection strategy offers the best patient outcomes (Table 1). In a prospective study, Abdelgawad and colleagues demonstrate excellent results utilizing MHCA with ACP. Although, these results were comparable to those of DHCA with RCP. ACP was correlated with both shorter clamp and ischemic times with no statistically significant difference in mortality and stroke rates. ${ }^{23}$ Other studies have also advocated for ACP as the strategy of choice. In a 2008 study, Apostolakis and colleagues investigated outcomes in 48 patients undergoing urgent aortic surgery for type A dissection. Their results concluded that ACP had a lower rate of stroke, earlier extubation, shorter ICU stay, and reduced costs. ${ }^{24}$ Wiedemann and colleagues analyze 329 patients undergoing aortic surgery for type A dissection and also found ACP to be associated with better short and long-term survival rates. ${ }^{25}$ However, several studies suggest RCP with DHCA to be equivalent, if not better, to ACP with MHCA. In a prospective, randomized study of 20 patients undergoing hemiarch replacement, Leshnower and colleagues used magnetic resonance imaging (MRI) to evaluate the incidence of brain injury. Despite no significant difference in clinically evident neurologic injury between patient who had MHCA with ACP and DHCA with RCP patients, the former had a higher incidence of radiographic neurologic injury $(\mathrm{n}=9,100 \%$ vs $\mathrm{n}=5,45 \%$; $=0.01) \cdot{ }^{26}$ Moreover, an STS database analysis of 7353 patients found that retrograde cerebral perfusion demonstrated a low risk of acute stroke in patients who underwent type A dissection repair. ${ }^{27}$ The literature is further obscured by multiple studies advocating one technique over the other. A large Society of Thoracic Surgeons database analysis evaluated 7830 patients undergoing hemiarch or total arch replacement from 2014 to 2016. The study excluded aortic dissections from the analysis. It concluded that in patients requiring more than 30 minutes of circulatory arrest, optimal strategies for cerebral protection include deep hypothermia with either antegrade or retrograde cerebral perfusion, or moderate hypothermia with antegrade cerebral perfusion. ${ }^{28}$ This conclusion essentially suggests that either strategy is acceptable as long as some form of cerebral perfusion is used. Furthermore, in a large study of 4,128 patients undergoing ascending aortic repair for Type A dissection in Japan, RCP had similar results in both mortality and neurologic outcomes when compared to ACP. ${ }^{29}$ Recently, minimally invasive surgical techniques have been applied to replacement of the ascending aorta and hemiarch at experienced centers. The majority of minimally invasive procedures reported are performed via an upper hemisternotomy (Fig. 3). ${ }^{30-32}$ In a mini-thoracotomy approach, cerebral perfusion is exclusively performed via RCP. ${ }^{33}$ The initial outcomes of the first reported minimally invasive, right mini-thoracotomy replacement of the ascending aorta and aortic valve in 20 patients was excellent; with no strokes, reoperations for bleeding, conversions to sternotomy or 30-day mortality. ${ }^{34}$ In 2018 , Lamelas and colleagues further described their experience with a sternal-sparing replacement of the ascending aorta with or without a concomitant aortic valve replacement via a right mini-thoracotomy in 74 patients. A propensity score-matched analysis was performed between 63 patients undergoing a sternotomy and an equivalent number of patients undergoing a minimally invasive non-sternotomy approach. The 30-day mortality was $3.2 \%$ in both groups, while stroke incidence was $0 \%$ in the minimally invasive group and $1 \%$ in the sternotomy group. Despite a longer circulatory arrest times in the minimally invasive group, stroke rate, as well as the transfusion requirements, ventilation times, as well as the ICU and hospital stays were less than the sternotomy group. ${ }^{35}$

\section{Conclusions}

The literature regarding the preferential use of antegrade versus retrograde cerebral perfusion during aortic surgery remains controversial. Analysis of many large databases in thoracic surgery have yielded excel- 
lent results for both cerebral protection strategies. The minimally invasive hemisternotomy or right minithoracotomy approach to replacement of the ascending aorta has also demonstrated excellent results. Future studies will be needed to compare sternotomy and minimally invasive approaches utilizing both antegrade and retrograde cerebral perfusion techniques.

\section{References}

1. Gilman S. CEREBRAL DISORDERS AFTER OPEN-HEART OPERATIONS. $N$ Engl $J$ Med 1965; 272 : 489-498. 1965/03/11. DOI: 10.1056/nejm196503112721001.

2. Patel BM, Reinert NJ, Al-Robaidi K, et al. Independent Predictors of Perioperative StrokeRelated Mortality after Cardiac Surgery. J Stroke Cerebrovasc Dis 2020: 104711. 2020/03/19. DOI: 10.1016/j.jstrokecerebrovasdis.2020.104711.

3. Puskas JD, Winston AD, Wright CE, et al. Stroke after coronary artery operation: incidence, correlates, outcome, and cost. Ann Thorac Surg 2000; 69: 1053-1056. 2000/05/09. DOI: 10.1016/s0003-4975(99)01569-6.

4. Misfeld M, Mohr FW and Etz CD. Best strategy for cerebral protection in arch surgery - antegrade selective cerebral perfusion and adequate hypothermia. Ann Cardiothorac Surg 2013; 2: 331-338. 2013/08/27. DOI: 10.3978/j.issn.2225-319X.2013.02.05.

5. Coselli JS and Green SY. Evolution of aortic arch repair. Tex Heart Inst J 2009; 36: 435-437. 2009/10/31.

6. De Bakey ME, Crawford ES, Cooley DA, et al. Successful resection of fusiform aneurysm of aortic arch with replacement by homograft.Surg Gynecol Obstet 1957; 105: 657-664. 1957/12/01.

7. Griepp RB, Stinson EB, Hollingsworth JF, et al. Prosthetic replacement of the aortic arch. J Thorac Cardiovasc Surg 1975; 70: 1051-1063. 1975/12/01.

8. Dumfarth J, Ziganshin BA, Tranquilli M, et al. Cerebral protection in aortic arch surgery: hypothermia alone suffices. Tex Heart Inst J2013; 40: 564-565. 2014/01/07.

9. Ziganshin BA and Elefteriades JA. Deep hypothermic circulatory arrest. Ann Cardiothorac Surg 2013; 2: 303-315. 2013/08/27. DOI: 10.3978/j.issn.2225-319X.2013.01.05.

10. Yan TD, Bannon PG, Bavaria J, et al. Consensus on hypothermia in aortic arch surgery. Annals of Cardiothoracic Surgery 2013; 2: 163-168.

11. Ueda Y. A reappraisal of retrograde cerebral perfusion. Ann Cardiothorac Surg 2013; 2: 316-325. 2013/08/27. DOI: 10.3978/j.issn.2225-319X.2013.01.02.

12. Ueda Y, Miki S, Kusuhara K, et al. Deep hypothermic systemic circulatory arrest and continuous retrograde cerebral perfusion for surgery of aortic arch aneurysm. Eur J Cardiothorac Surg 1992; 6: 36-41; discussion 42. 1992/01/01. DOI: 10.1016/1010-7940(92)90096-g.

13. Kaneda T, Saga T, Onoe M, et al. Antegrade selective cerebral perfusion with mild hypothermic systemic circulatory arrest during thoracic aortic surgery. Scand Cardiovasc J 2005; 39: 87-90. 2005/08/16. DOI: $10.1080 / 14017430410004614$.

14. Ganapathi AM, Hanna JM, Schechter MA, et al. Antegrade versus retrograde cerebral perfusion for hemiarch replacement with deep hypothermic circulatory arrest: Does it matter? A propensitymatched analysis. Journal of Thoracic and Cardiovascular Surgery 2014; 148: 2896-2902. Article. DOI: 10.1016/j.jtcvs.2014.04.014.

15. Di Marco L, Murana G, Leone A, et al. Con-debate: short circulatory arrest times in arch reconstructive surgery: is simple retrograde cerebral perfusion or hypothermic circulatory arrest as good or better than complex antegrade cerebral perfusion for open distal involvement or hemi-arch? J Vis Surg 2018; 4: 46. 2018/04/24. DOI: 10.21037/jovs.2018.01.18. 
16. Anttila V, Pokela M, Kiviluoma K, et al. Is maintained cranial hypothermia the only factor leading to improved outcome after retrograde cerebral perfusion? An experimental study with a chronic porcine model.J Thorac Cardiovasc Surg 2000; 119: 1021-1029. 2000/05/02. DOI: 10.1016/s0022-5223(00)70098-5.

17. Hagl C, Khaladj N, Karck M, et al. Hypothermic circulatory arrest during ascending and aortic arch surgery: the theoretical impact of different cerebral perfusion techniques and other methods of cerebral protection. Eur J Cardiothorac Surg 2003; 24: 371-378. 2003/09/11. DOI: 10.1016/s1010-7940(03)00337-3.

18. Tanaka A and Estrera AL. Simple retrograde cerebral perfusion is as good as complex antegrade cerebral perfusion for hemiarch replacement.J Vis Surg 2018; 4: 50. 2018/04/24. DOI: 10.21037/jovs.2018.02.10.

19. Malvindi PG, Scrascia G and Vitale N. Is unilateral antegrade cerebral perfusion equivalent to bilateral cerebral perfusion for patients undergoing aortic arch surgery? Interact Cardiovasc Thorac Surg 2008; 7: 891-897. 2008/07/23. DOI: 10.1510/icvts.2008.184184.

20. Lamelas J, Aberle C, Macias A, et al. Cannulation Strategies for Minimally Invasive Cardiac Surgery. Innovations (Phila) 2020. DOI: 10.1177/1556984520911917.

21. Reich DL, Uysal S, Ergin MA, et al. Retrograde cerebral perfusion as a method of neuroprotection during thoracic aortic surgery. Ann Thorac Surg 2001; 72: 1774-1782. 2001/11/28. DOI: 10.1016/s00034975(01)02718-7.

22. Lamelas J and LaPietra A. Right Minithoracotomy Approach for Replacement of the Ascending Aorta, Hemiarch, and Aortic Valve.Innovations (Phila) 2016; 11: 301-304. 2016/09/20. DOI: 10.1097/imi.000000000000292.

23. Abdelgawad A and Arafat H. Moderate versus deep hypothermic circulatory arrest for ascending aorta and aortic arch surgeries using open distal anastomosis technique. Journal of the Egyptian Society of CardioThoracic Surgery 2017; 25: 323-330. Article. DOI: 10.1016/j.jescts.2017.11.006.

24. Apostolakis E, Koletsis EN, Dedeilias P, et al. Antegrade versus retrograde cerebral perfusion in relation to postoperative complications following aortic arch surgery for acute aortic dissection type A. Journal of Cardiac Surgery 2008; 23: 480-487. DOI: 10.1111/j.1540-8191.2008.00587.x.

25. Wiedemann D, Kocher A, Dorfmeister M, et al. Effect of cerebral protection strategy on outcome of patients with Stanford type A aortic dissection. Journal of Thoracic and Cardiovascular Surgery 2013; 146: 647-655.e641. Article. DOI: 10.1016/j.jtcvs.2012.07.072.

26. Leshnower BG, Rangaraju S, Allen JW, et al. Deep Hypothermia With Retrograde Cerebral Perfusion Versus Moderate Hypothermia With Antegrade Cerebral Perfusion for Arch Surgery. Annals of Thoracic Surgery2019; 107: 1104-1110. Article. DOI: 10.1016/j.athoracsur.2018.10.008.

27. Ghoreishi M, Sundt TM, Cameron DE, et al. Factors associated with acute stroke after type A aortic dissection repair: An analysis of the Society of Thoracic Surgeons National Adult Cardiac Surgery Database. Journal of Thoracic and Cardiovascular Surgery 2019. Article in Press. DOI: 10.1016/j.jtcvs.2019.06.016.

28. Itagaki S, Chikwe J, Sun E, et al. Impact of Cerebral Perfusion on Outcomes of Aortic Surgery: STS Adult Cardiac Database Analysis. The Annals of thoracic surgery 2019. Article in Press. DOI: 10.1016/j.athoracsur.2019.08.043.

29. Tokuda Y, Miyata H, Motomura N, et al. Brain protection during ascending aortic repair for stanford type A acute aortic dissection surgery - Nationwide analysis in Japan. Circulation Journal 2014; 78: 2431-2438. Article. DOI: 10.1253/circj.CJ-14-0565.

30. Hastaoglu IO, Tokoz H, Ozgen A, et al. Proximal Aortic Surgery: Upper "J" or Conventional Sternotomy? Heart Surg Forum 2018; 21: E004-e008. 2018/02/28. DOI: 10.1532/hsf.1649.

31. Tabata M, Khalpey Z, Aranki SF, et al. Minimal access surgery of ascending and proximal arch of the aorta: a 9-year experience. Ann Thorac Surg 2007; 84: 67-72. 2007/06/26. DOI: 
10.1016/j.athoracsur.2007.03.029.

32. Wu Y, Jiang W, Li D, et al. Surgery of ascending aorta with complex procedures for aortic dissection through upper mini-sternotomy versus conventional sternotomy. J Cardiothorac Surg 2020; 15: 57. 2020/04/09. DOI: 10.1186/s13019-020-01095-1.

33. Lamelas J, Abrele C, Macias A, et al. Cannulation Strategies for Minimally Invasive Cardiac Surgery. Innovations (Phila) 2020. DOI: 10.1177/1556984520911917.

34. LaPietra A, Santana O, Pineda AM, et al. Outcomes of aortic valve and concomitant ascending aorta replacement performed via a minimally invasive right thoracotomy approach. Innovations (Phila) 2014; 9: 339-342; discussion 342. 2014/09/25. DOI: 10.1097/imi.0000000000000099.

35. Lamelas J, Chen PC, Loor G, et al. Successful Use of Sternal-Sparing Minimally Invasive Surgery for Proximal Ascending Aortic Pathology.Ann Thorac Surg 2018; 106: 742-748. 2018/05/08. DOI: 10.1016/j.athoracsur.2018.03.081.

36. Apaydin AZ, Islamoglu F, Askar FZ, et al. Immediate clinical outcome after prolonged periods of brain protection: Retrospective comparison of hypothermic circulatory arrest, retrograde, and antegrade perfusion.Journal of Cardiac Surgery 2009; 24: 486-489. Article. DOI: 10.1111/j.1540-8191.2008.00772.x.

37. Soliman S, Farouk AE, Elsharkawy A, et al. Hospital outcomes of antegrade versus retrograde arterial cannulation in type A aortic dissection: Single center experience. Journal of the Egyptian Society of CardioThoracic Surgery 2018; 26: 270-275. Article. DOI: 10.1016/j.jescts.2018.11.002.

38. Stevens L, Madsen JC, Isselbacher EM, et al. Surgical management and long-term outcomes for acute ascending aortic dissection. Journal of Thoracic and Cardiovascular Surgery 2009; 138: 1349-1357.e1341. Article. DOI: 10.1016/j.jtcvs.2009.01.030.

39. Sundt ITM, Orszulak TA, Cook DJ, et al. Improving Results of Open Arch Replacement. Annals of Thoracic Surgery 2008; 86: 787-796. Article. DOI: 10.1016/j.athoracsur.2008.05.011.

40. Sugiura T, Imoto K, Uchida K, et al. Comparative study of brain protection in ascending aorta replacement for acute type A aortic dissection: Retrograde cerebral perfusion versus selective antegrade cerebral perfusion. General Thoracic and Cardiovascular Surgery2012; 60: 645-648. Article. DOI: 10.1007/s11748012-0142-z.

41. Usui A, Miyata H, Ueda Y, et al. Risk-adjusted and case-matched comparative study between antegrade and retrograde cerebral perfusion during aortic arch surgery: Based on the Japan adult cardiovascular surgery database: The Japan cardiovascular surgery database organization. General Thoracic and Cardiovascular Surgery 2012; 60: 132-139. Article. DOI: 10.1007/s11748-011-0857-2.

Table 1: Antegrade vs, retrograde cerebral perfusion strategies mortality and stroke morbidity outcomes.

\section{Study}

Abdelgawad A, et al $2017^{23}$

Apaydin AZ, et al. $2009^{36}$

Apostolakis E, et. al $2008^{24}$

Ganapathi AM, et al $2014^{14}$

Ghoreishi M, et al. $2019^{27}$

Itagaki S, et al. $2019^{28}$

Leshnower BG, 201926

Soliman S, et al. $2018^{37}$

Stevens L, et al. $2009{ }^{38}$

Sundt TM III, et al. $2008^{39}$

Sugiura T, et al. $2012^{40}$

\section{$\mathbf{N}=$}

43

239

48

440

7353

7830

20

50

195

347

203 
Tokuda Y, et al. $2014^{29}$

\section{Figure legends}

Figure 1: Estimated safe duration of DHCA (HCA). From Yan et al (Permitted third party reuse by the CC BY-NC-ND 4.0 license).Figure 2: Retrograde cerebral perfusion via SVC cannulation, with venous drainage through the bicaval cannula during the cooling phase. From Gravlee: Cardiopulmonary Bypass, $2^{\text {nd }}$ Ed. Wolters Kluwer, 2000.Figure 3: Retrograde cerebral perfusion in a minimally invasive approach setting: (A) Right lateral mini-thoracotomy incision entering the 4th intercostal space. Patient's arm is always positioned over the head; (B) Surgical field exposure with the SVC cannula in place and a completed hemiarch anastomosis.

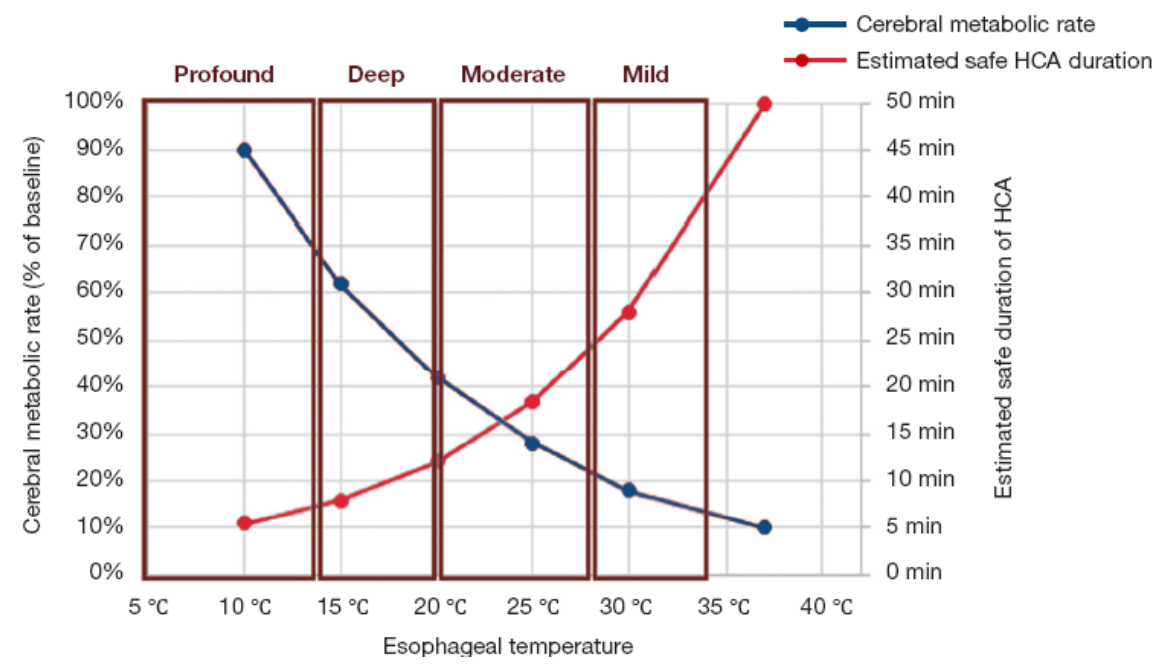




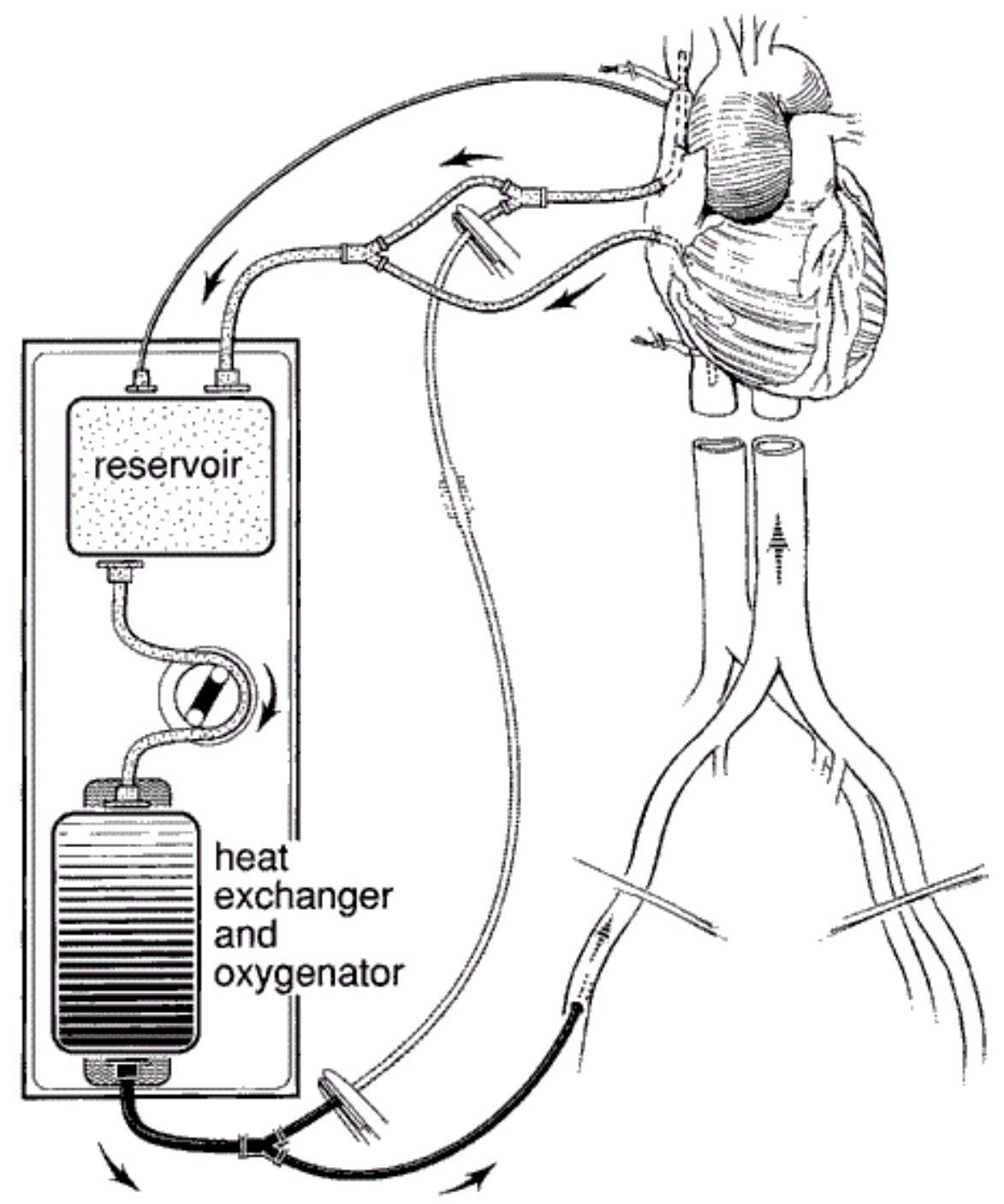



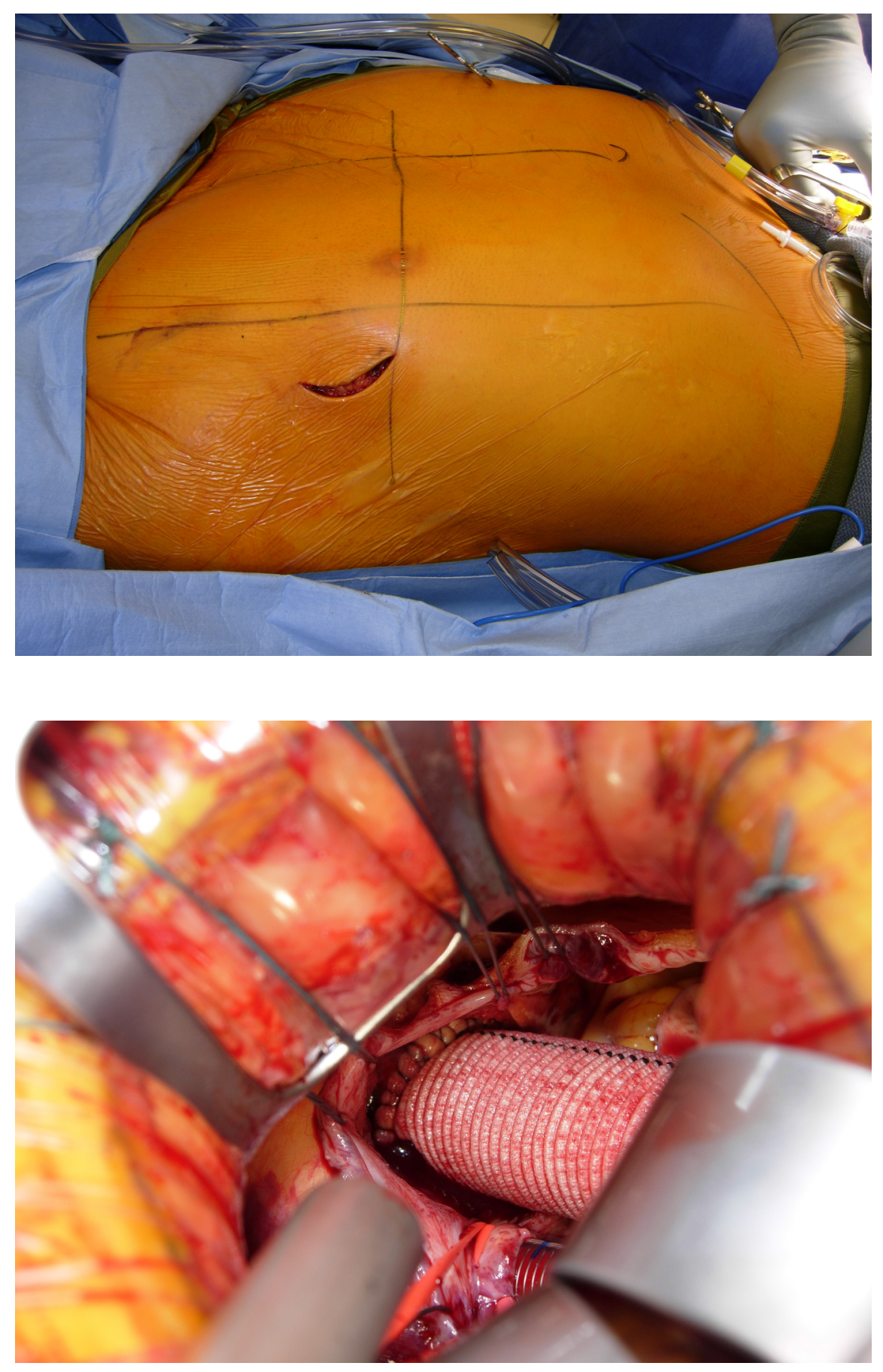